\title{
PENGARUH BRAND IMAGE DAN BRAND TRUST TERHADAP MINAT BELI DI SOCIOLLA DI JAKARTA
}

\author{
Stella \\ Program Studi Magister Manajemen Universitas Tarumanagara \\ anastasiastellas@gmail.com
}

Masuk : 05-12-2020, revisi : 14-12-2020, diterima untuk diterbitkan : 15-12-2020

\begin{abstract}
The writing of this research begins with the importance of an image and brand trust in a brand that can be built by the company. A brand is considered the main pillar and invisible asset in a company. The high awareness and knowledge of a brand will make it easier for businesses to achieve and even exceed the goals in a short time limit. Therefore, a brand must have a good image in the eyes of consumers. Positive brand image will build brand trust in using the products or services of the brand. Brand trust is also the main element that companies must have to increase consumer purchase intentions. Without trust, the brand cannot perform well in all types of markets that the brand is targeting. Thus, this research aims to determine whether or not the influence of brand image and brand trust affects purchase intention. This research uses quantitative methods by distributing questionnaires to 106 respondents and uses non-probability sampling techniques in the form of purposive sampling. The results of this research indicate that the brand image variable $(\mathrm{X} 1)$ and brand trust $(\mathrm{X} 2)$ have a significant effect on the purchase intention variable (Y) of 0.568 or $56.8 \%$. Meanwhile, the remaining $43.2 \%$ means only other factors that are not included in this study.
\end{abstract}

Keywords: Brand Image, Brand Trust, Purchase Intention, Sociolla

Abstrak: Penulisan penelitian ini berawal dari pentingnya sebuah citra dan kepercayaan konsumen pada suatu brand yang dapat dibangun oleh perusahaan. Brand dianggap sebagai pilar utama dan aset yang tak terlihat dalam suatu perusahaan. Tingginya kesadaran dan pengetahuan terhadap suatu brand, akan mempermudah pebisnis untuk mencapai tujuan dan melampaui pesaing dengan upaya dan waktu yang singkat. Brand image yang positif akan membangun brand trust atau kepercayaan konsumen untuk menggunakan produk atau jasa dari brand tersebut. Brand trust juga menjadi unsur utama yang harus dimiliki perusahaan untuk meningkatkan niat beli konsumen. Tanpa adanya trust, brand tersebut tidak dapat berjalan dengan baik di segala jenis pasar yang ditargetkan oleh brand tersebut. Dengan demikian, penelitian ini bertujuan untuk mengetahui ada atau tidaknya pengaruh dari brand image dan brand trust terhadap minat beli. Penelitian ini menggunakan metode kuantitatif dengan menyebarkan kuesioner pada 106 responden dan menggunakan teknik non-probability sampling dalam bentuk sampling purposif. Hasil dari penelitian menunjukkan bahwa variabel brand image (X1) dan brand trust (X2) berpengaruh secara signifikan terhadap variabel minat beli (Y) sebesar 0,568 atau 56,8\%. Sedangkan, sisa 43,2\% berarti dipengaruhi oleh faktorfaktor lain yang tidak termasuk dalam penelitian ini.

Kata Kunci: Brand Image, Brand Trust, Minat Beli, Sociolla 


\section{PENDAHULUAN}

Pesatnya laju pertumbuhan ekonomi dan pasar yang terus berkembang, mendorong persaingan yang ketat antar perusahaan. Ditambah lagi dengan adanya perkembangan teknologi saat ini, tentunya akan memberikan pengaruh yang cukup signifikan bagi perusahaan dalam memasarkan produk-produk yang dijual agar dapat diterima oleh konsumen dengan berbagai cara.

Perusahaan harus terus berfokus pada pelanggan, sebagai sumber utama penghasilan agar dapat mencapai target tertentu. Sehubungan dengan hal tersebut, minat beli konsumen terhadap suatu brand sangat penting untuk diperhatikan. Minat beli diartikan sebagai perilaku konsumen yang disebabkan oleh rangsangan faktor eksternal dan karakter pribadi masing-masing individu (Kotler \& Keller, 2016).

Menurut Saad et al. (2012) melalui jurnal yang ditulis, minat beli dipengaruhi secara signifikan oleh brand image. Alif Fianto (2014) juga menyatakan bahwa brand image merupakan faktor yang berpengaruh secara positif terhadap minat beli. Ditambah lagi dengan faktor lain yaitu brand trust yang menjadi penghubung kedua variabel tersebut. Menurut Aydin et al. (2014), brand trust merupakan faktor yang memiliki pengaruh paling tinggi terhadap minat beli. Dalam penelitian ini, brand image dan brand trust akan diimplementasikan di salah satu situs atau platform jual-beli kosmetik online yang berada di Jakarta, Indonesia yaitu Sociolla. Peneliti ingin melihat ada tidaknya pengaruh brand image dan brand trust terhadap minat beli konsumen di Sociolla.

\section{Tujuan Penelitian}

Tujuan penelitian ini untuk mengetahui ada tidaknya pengaruh brand image dan brand trust terhadap minat beli di Sociolla khususnya di Jakarta. Hasil penelitian ini diharapkan dapat membantu perusahaan untuk terus memperhatikan brand image dan brand trust agar meningkatkan minat beli konsumen terhadap suatu produk.

\section{TINJAUAN PUSTAKA}

\section{Brand Image}

Menurut Kotler dan Keller (2012, p. 248), "Brand Imagery describes the extrinsic properties of the product or service, including the ways in which the brand attempts to meet customers ' psychological or social needs". Hal ini menjelaskan bahwa citra merek merupakan persepsi konsumen terhadap suatu brand yang telah terbentuk dipikiran masing-masing individu sesuai dengan bagaimana brand ingin dilihat di mata konsumen dan memenuhi kebutuhan mereka.

\section{Brand Trust}

Menurut Aaker dan Kumar (2008, p. 69), brand trust merupakan faktor penting dalam meningkatkan minat pembelian, brand trust diartikan sebagai kerelaan individu mempercayai kemampuan brand untuk memenuhi kebutuhannya.

\section{Minat Beli}

Menurut Kotler dan Keller (2016), minat beli merupakan perilaku konsumen yang ingin membeli produk atau jasa yang disebabkan oleh rangsangan faktor eksternal dan karakter pribadi masing-masing individu.

\section{Kerangka Pemikirian \& Hipotesis Penelitian}

Berikut merupakan kerangka pemikiran dan hipotesis dalam penelitian ini: 


\section{Gambar 1 \\ Kerangka Pemikiran}

Sumber: Hasil olahan peneliti SPSS 22, 2020

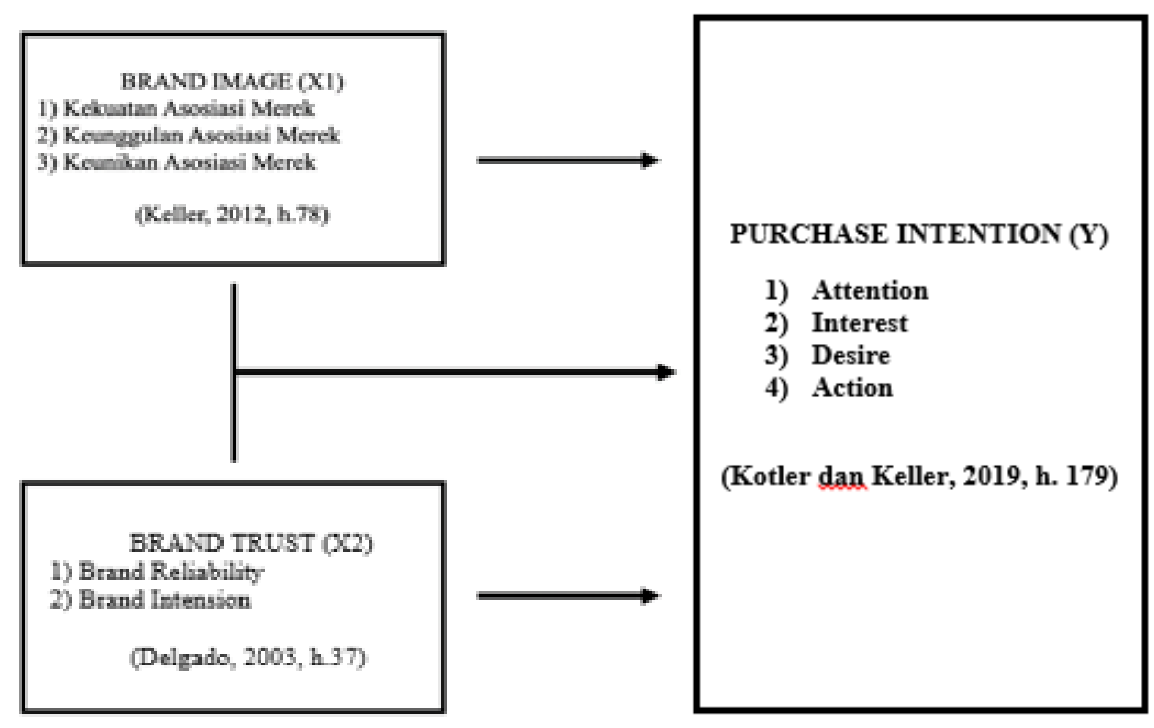

\section{METODOLOGI PENELITIAN}

Penelitian ini menggunakan metode kuantitatif dengan cara survei, yang berarti menggunakan kuesioner sebagai teknik utama untuk mengumpulkan data. Sifat penelitian yang digunakan yaitu eksplanatif. Sifat penelitian ini dipilih berdasarkan hubungan sebab dan akibat dari ketiga variabel yang sudah ditentukan. Teknik pengumpulan data melalui kuesioner disebar kepada 106 responden dan diolah menggunakan SPSS.

\section{Hasil Uji Statistik}

\section{Uji Normalitas}

\section{Gambar 2}

Hasil Uji Normalitas P-Plot

Sumber: Hasil olahan peneliti SPSS 22, 2020

Normal P.P Plot of Regression Standardized Residual

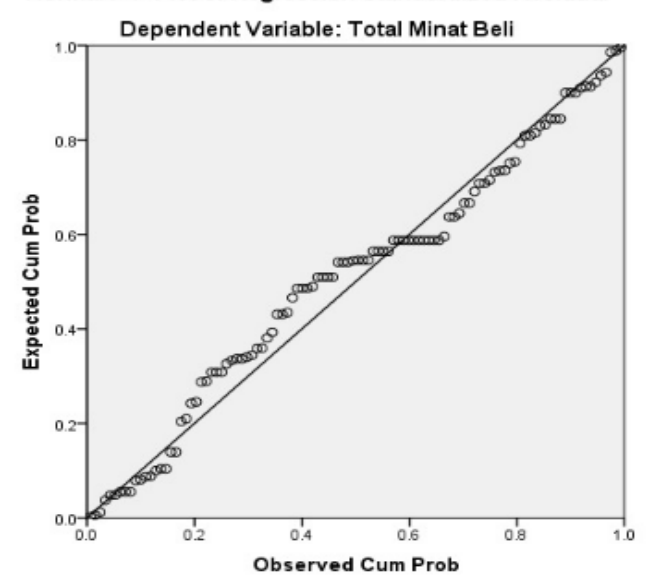

Berdasarkan uji normalitas dari gambar diatas, terlihat hasil grafik P-Plot memiliki pola plotting yang dekat dengan garis diagonal. Dapat disimpulkan model regresi memenuhi syarat normalitas P-Plot. 


\section{Uji Multikolinearitas}

\section{Gambar 3}

Hasil Uji Multikolinearitas

Sumber: Hasil olahan peneliti SPSS 22, 2020

\begin{tabular}{|c|c|c|c|c|c|c|c|c|}
\hline \multicolumn{9}{|c|}{ Coefficients $^{a}$} \\
\hline \multirow[b]{2}{*}{ Model } & & \multicolumn{2}{|c|}{ Unstandardized Coefficients } & \multirow{2}{*}{$\begin{array}{c}\text { Standardized } \\
\text { Coefficients }\end{array}$} & \multirow[b]{2}{*}{$t$} & \multirow[b]{2}{*}{ Sig. } & \multicolumn{2}{|c|}{ Collinearity Statistics } \\
\hline & & $\mathrm{B}$ & Std. Error & & & & Tolerance & VIF \\
\hline 1 & (Constant) & -1.285 & 1.644 & & -.782 & .436 & & \\
\hline & Total Brand Image & .264 & .142 & .198 & 1.857 & .066 & .368 & 2.719 \\
\hline & Total Brand Trust & .623 & .114 & .586 & 5.483 & .000 & .368 & 2.719 \\
\hline
\end{tabular}

a. Dependent Variable: Total Minat Beli

Berdasarkan gambar diatas, dapat dilihat hasil tolerance adalah 0.368 untuk Brand Image dan Brand Trust yang berarti lebih besar dari 0,100. Oleh karena itu, kesimpulannya adalah tidak ada gejala multikolinearitas.

\section{Uji Heteroskedastisitas}

\section{Gambar 4}

Hasil Uji Heteroskedastisitas

Sumber: Hasil olahan peneliti SPSS 22, 2020

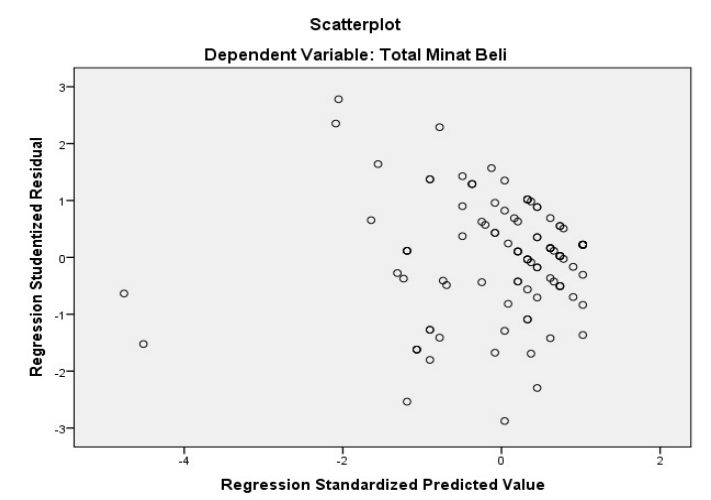

Berdasarkan gambar diatas, dapat dilihat bahwa titik-titik menyebar diatas dan dibawah atau disekitar angka 0 . Penyebaran titik-titik juga tidak membentuk suatu pola tertentu. Maka, hasil uji tidak ada masalah heteroskedastisitas.

\section{Analisis Koefisien Determinasi $\left(\mathbf{R}^{2}\right)$}

\section{Gambar 5}

\section{Hasil Uji Koefisien Determinasi}

Sumber: Hasil olahan peneliti SPSS 22, 2020

\section{Model Summary}

\begin{tabular}{|l|l|r|r|r|r|}
\hline Model & $\mathrm{R}$ & R Square & \multicolumn{1}{|c|}{$\begin{array}{c}\text { Adjusted R } \\
\text { Square }\end{array}$} & $\begin{array}{c}\text { Std. Error of } \\
\text { the Estimate }\end{array}$ & $\begin{array}{l}\text { Durbin- } \\
\text { Watson }\end{array}$ \\
\hline 1 & $.753^{\mathrm{a}}$ & .568 & .559 & 1.90726 & 1.653 \\
\hline
\end{tabular}

a. Predictors: (Constant), Total Brand Trust, Total Brand Image

b. Dependent Variable: Total Minat Beli

R Square yang diperoleh sebesar 0,568. Berarti kontribusi Brand Image (X1) dan Brand Trust (X2) memiliki pengaruh sebesar 56,8\% terhadap Minat Beli. Sedangkan, sisa 43,2\% dipengaruhi oleh faktor lain yang tidak termasuk dalam penelitian ini. 


\section{Hasil Uji F}

\section{Gambar 6 \\ Hasil Uji F}

Sumber: Hasil olahan peneliti SPSS 22, 2020

\begin{tabular}{|ll|r|r|r|r|r|}
\hline \multicolumn{1}{|l|}{ ANOXA $^{\mathrm{a}}$} \\
\hline 1 & Sum of Squares & \multicolumn{1}{c|}{$\mathrm{df}$} & Mean Square & \multicolumn{1}{c|}{ F } & Sig. \\
\hline & Regression & 491.699 & 2 & 245.850 & 67.585 & $.000^{\mathrm{b}}$ \\
& Residual & 374.678 & 103 & 3.638 & & \\
& Total & 866.377 & 105 & & & \\
\hline
\end{tabular}

a. Dependent Variable: Total Minat Beli

b. Predictors: (Constant), Total Brand Trust, Total Brand Image

Berdasarkan tabel anova, nilai signifikansi nya adalah 0,000 lebih kecil dari 0,05. Maka, Brand Image dan Brand trust secara bersama-sama berpengaruh terhadap minat beli.

\section{Hasil Uji T}

\section{Gambar 5 \\ Hasil Uji T}

Sumber: Hasil olahan peneliti SPSS 22, 2020

\begin{tabular}{|c|c|c|c|c|c|c|c|c|}
\hline \multirow{2}{*}{\multicolumn{2}{|c|}{ Model }} & \multicolumn{2}{|c|}{ Unstandardized Coefficients } & \multirow{2}{*}{$\begin{array}{c}\text { Standardized } \\
\text { Coefficients }\end{array}$} & \multirow[b]{2}{*}{$t$} & \multirow[b]{2}{*}{ Sig. } & \multicolumn{2}{|c|}{ Collinearity Statistics } \\
\hline & & $\mathrm{B}$ & Std. Error & & & & Tolerance & VIF \\
\hline \multirow[t]{3}{*}{1} & (Constant) & -1.285 & 1.644 & & -.782 & .436 & & \\
\hline & Total Brand Image & .264 & .142 & .198 & 1.857 & .066 & .368 & 2.719 \\
\hline & Total Brand Trust & .623 & .114 & .586 & 5.483 & .000 & .368 & 2.719 \\
\hline
\end{tabular}

Berdasarkan tabel diatas, nilai Signifikansi pada Brand Image adalah 0,066 dan Brand Trust 0,000. Sehingga, kesimpulan uji parsial brand image tidak berpengaruh terhadap minat beli, dan variabel brand trust berpengaruh terhadap minat beli.

\section{HASIL DAN KESIMPULAN}

Hasil penelitian yang diolah menggunakan SPSS versi 22 menunjukkan bahwa uji validitas dan uji reliabilitas telah memenuhi syarat valid dan reliabel dengan memiliki $r$ hitung lebih dari $r$ tabel 0,195 dan Cronbach Alpha lebih besar dari 0.6.

Hasil dari uji antar variabel brand image dengan minat beli, menunjukkan nilai t hitung sebesar 1,857 dan t tabel memiliki nilai sebesar 1,986 yang berarti tidak sesuai dan lebih besar dari t hitung. Pengambilan keputusan juga dapat dilihat dari nilai signifikansi variabel brand image sebesar 0,066 yang berarti lebih dari tingkat signifikansi 0,05. Oleh karena itu, dapat disimpulkan variabel brand image secara parsial tidak berpengaruh signifikan terhadap variabel minat beli di Sociolla di Jakarta. Hal ini mungkin terjadi dikarenakan faktor-faktor lainnya. Seperti, brand image Sociolla belum terlalu melekat di benak masyarakat ketika ingin membeli produk kecantikan, yang berarti Sociolla belum menjadi market leader di bidangnya.

Dasar pengambilan keputusan ditentukan oleh hasil t hitung $>\mathrm{t}$ tabel. Hasil dari uji antar variabel brand trust dengan minat beli, menunjukkan nilai t hitung sebesar 5,483 dan t tabel memiliki nilai sebesar 1,986 yang berarti sesuai dan lebih kecil dari t hitung. Pengambilan keputusan juga dilihat dari nilai signifikansi variabel brand trust sebesar 0,000 yang berarti tidak melebihi 0,05. Oleh karena itu, dapat disimpulkan bahwa variabel brand trust secara parsial berpengaruh terhadap minat beli di Sociolla di Jakarta. Hal ini artinya minat beli konsumen terhadap produk-produk di Sociolla didasarkan pada kepercayaan konsumen. Karena produk yang dijual sudah pasti terjamin, maka dari itu konsumen tidak meragukan kualitasnya. 


\section{SARAN}

Saran dari peneliti, Sociolla harus lebih meningkatkan brand image yang dimiliki agar lebih dikenal oleh masyarakat luas yang nantinya bias meningkatkan atau mempengaruhi keputusan pembelian konsumen. Dikarenakan brand image yang dimiliki Sociolla kurang melekat dibenak masyarakat, konsumen bisa saja lebih memilih tempat lain untuk memembeli kebutuhan produk kecantikan yang dibutuhkan.

Berdasarkan hasil penelitian pada variabel brand trust, ditunjukkan adanya pengaruh yang signifikan. Hal ini berarti minat beli yang ada pada konsumen disebabkan oleh kepercayaan yang dibangun antara Sociolla dengan konsumen. Saran dari peneliti yaitu untuk terus mempertahankan kepercayaan yang telah dibangun antara perusahaan dan konsumen.

Saran untuk penelitian selanjutnya, diharapkan untuk lebih mengembangkan variabelvariabel lainnya yang lebih sesuai dan dapat berpengaruh terhadap minat beli di Sociolla di Jakarta. Sehingga, variabel brand trust akan menjadi variabel tambahan saja di penelitian berikutnya dan dapat bermanfaat bagi minat beli di perusahaan.

\section{DAFTAR PUSTAKA}

Aaker, D. A., Kumar, V., \& Day, G. S. (2008). Marketing research (9th ed.). John Wiley \& Sons.

Alif Fianto, A. Y., Hadiwidjojo, D., Aisjah, S., \& Solimun, S. (2014). The influence of brand image on purchase behaviour through brand trust. Business Management and Strategy, 5(2), 58. https://doi.org/10.5296/bms.v5i2.6003

Aydin, G., AR, A. A., \& Taskin, Ç. (2014). The role of brand trust on parents purchase intentions of baby-care products. Doğuş Üniversitesi Dergisi, 2(15), 165-180. https://doi.org/10.31671/dogus.2018.84

Kotler, P., \& Keller, K. L. (2012). Manajemen pemasaran (12th ed.). Erlangga.

Kotler, P., \& Keller, K. L. (2016). Marketing management (15th ed.). Pearson Education, Inc.

Shah, S. S. H., Aziz, J., Jaffari, A. R., Waris, S., Ejaz, W., Fatima, M., \& Sherazi, S. K. (2012). The impact of brands on consumer purchase intentions. Asian Journal of Business Management, 4(2), 105-110. https://maxwellsci.com/print/ajbm/v4-105110.pdf 